\title{
9-Anthraldehyde oxime: a synthetic tool for variable applications
}

\author{
Sarbast M. Ahmed ${ }^{1}$ Faiq H. S. Hussain ${ }^{2} \cdot$ Paolo Quadrelli $^{3}$ (1)
}

Received: 15 April 2020 / Accepted: 23 September 2020 / Published online: 5 November 2020

(c) The Author(s) 2020

\begin{abstract}
Oximes are one of the most important and prolific functional groups in organic chemistry; among them, 9-anthraldehyde oxime represents a valuable example both from the preparative side and the synthetic applications. There are many strategies to prepare 9-anthraldehyde oxime from different functional groups that were summarized in the present review, focusing on the most recent and innovative. The main synthetic applications of 9-anthraldehyde oxime are presented and thoroughly discussed, focusing on the most recent and innovative synthetic strategies.
\end{abstract}

\section{Graphic abstract}

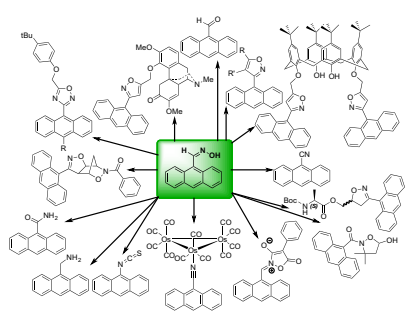

Keywords Anthracene aldehyde $\cdot$ Oxime $\cdot$ Synthesis $\cdot$ Synthetic applications

\section{Introduction}

Oximes represent an important and interesting class of organic compounds, with a wide range of applications [1]; typically, protection, purification, and characterization of carbonyl compounds are the traditional uses of these derivatives [2]. In addition, they can be converted into nitriles, nitro compounds, nitrones, amines, amides and they can also be exploited in the synthesis of azaheterocycles. 9-Anthraldehyde oxime (CAS n 34810-13-4) has not been studied so far; therefore a limited or very few publications describe

Paolo Quadrelli

paolo.quadrelli@unipv.it

1 Department of Pharmaceutical Chemistry, Pharmacy

College, Hawler Medical University, Erbil,

Kurdistan Region, Iraq

2 Medical Analysis Department, Faculty of Science, Tishk International University, Erbil, Kurdistan Region, Iraq

3 Department of Chemistry, University of Pavia, Viale Taramelli 12, 27100 Pavia,, Italy the uses of this molecule in organic chemistry. 9-Anthraldehyde oxime is a primary material for the preparation of a large number of cyclic and heterocyclic compounds, for instance, isoxazoles, isoxazolines, isoxazolidines, as well as organic compounds such as aldehydes, amides, amines, and nitriles. This review will cover a research area whose impact in current organic synthesis can be evaluated from Fig. 1 that reports the literature dealing with the main topics that compose the present work.

9-Anthraldehyde oxime is a commercially available product that was first synthesized by Hinkel and co-authors [3] in 1935 (m.p. $186-187^{\circ} \mathrm{C}$ ). In repeating the preparation of the same compound by Fieser and Hartwell used a different procedure that afforded the desired compound in $93 \%$ yield with a different melting point of $165^{\circ} \mathrm{C}$ [4].

Meek and Dann [5] prepared both the syn- and antiisomer of 9-anthraldehyde oxime (Fig. 2) through another different procedure; they first repeated the Fieser's procedure by neutralizing hydroxylamine with sodium carbonate, resulting in the same compound with the melting point of 
Fig. 1 Main topics and literature distribution from 1970 to 2020

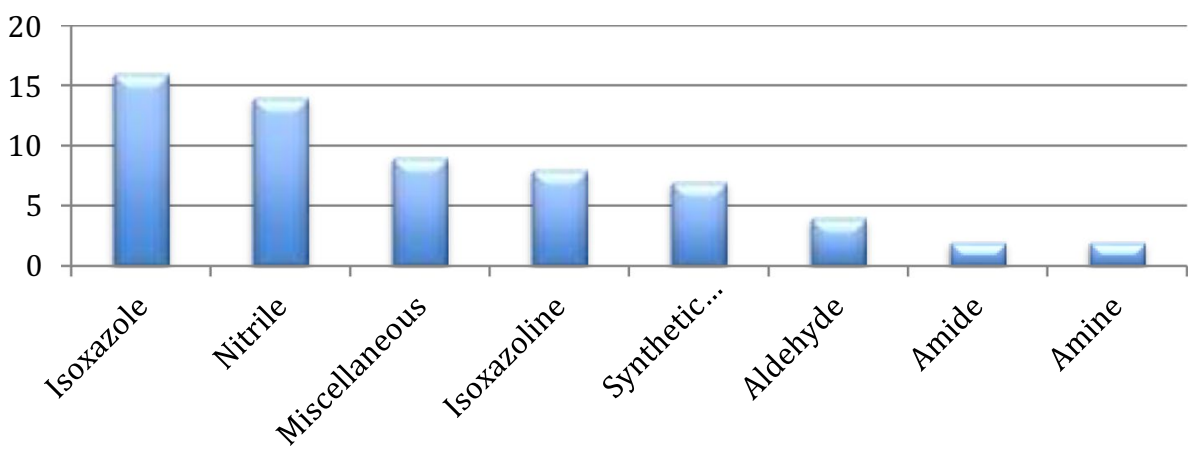

Fig. 2 9-Anthraldehyde oxime, syn $(Z)$ and anti $(E)$ isomers<smiles>C/C(=N\O)c1c2ccccc2cc2ccccc12</smiles>

(Z)-Anthracene-9-carbaldehyde oxime<smiles>O/N=C/c1c2ccccc2cc2ccccc12</smiles>

(E)-Anthracene-9-carbaldehyde oxime
Scheme 1<smiles>Cc1c2ccccc2cc2ccccc12</smiles>

1
$\mathrm{NHPI} / \mathrm{TBN}, \mathrm{Cu}(\mathrm{OAc})_{2}$

$\mathrm{MeCN}, 80^{\circ} \mathrm{C}, 24 \mathrm{~h}$

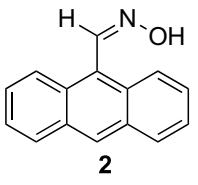

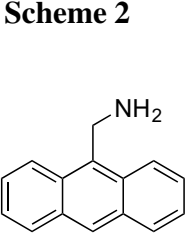

3

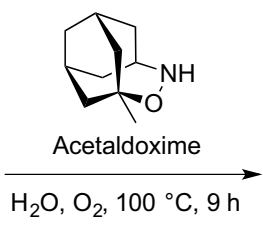

$\mathrm{H}_{2} \mathrm{O}, \mathrm{O}_{2}, 100{ }^{\circ} \mathrm{C}, 9 \mathrm{~h}$<smiles>O/N=C/c1c2ccccc2cc2ccccc12</smiles>

2 $165^{\circ} \mathrm{C}$. For the isolation of the anti isomer, the hydroxylamine hydrochloride was neutralized in 50\% ethanolic pyridine and coupled with the aldehyde, affording the anti oxime with a melting point of $218-220^{\circ} \mathrm{C}$. Moreover, the anti isomer can be also prepared from the syn isomer by heating an EtOH solution at $75^{\circ} \mathrm{C}$ for a few hours. The oxime isomers are soluble in sodium hydroxide solutions and can be reprecipitated with $\mathrm{HCl}$. Upon heating with acetic anhydride for $10 \mathrm{~min}$, the syn isomer affords the corresponding acetate while the anti isomer gives the 9-cyanoanthracene.

Besides the classical preparation method from aldehyde and hydroxylamine, other synthetic approaches can be found in the literature. The preparation of 9-anthraldehyde oxime (2) has been described in two different ways by Yu and coauthors [6, 7]. In a first method, 9-methylanthracene (1) was treated with $N$-hydroxyphthalimide (NHPI) and tert-butyl nitrite (TBN) in acetonitrile as a solvent under nitrogen at $80{ }^{\circ} \mathrm{C}$ for $24 \mathrm{~h}$ in the presence of $\mathrm{Cu}(\mathrm{OAc})_{2}$ as the catalyst; the 9 -anthraldehyde oxime (2) was obtained in $85 \%$ yield (Scheme 1).

This methodology proceeds under mild conditions and tolerates a wide range of substrates, affording the targeted aromatic oximes in 63-86\% yields. In the second procedure, oxime 2 was prepared to start from the anthracen9-ylmethanamine (3) under aerobic condition, using 3-methyl-4-oxa-5-azahomoadamantane as the catalyst, acetaldoxime as co-catalyst, water as solvent and oxygen as oxidant. The anti isomer of $\mathbf{2}$ was formed with excellent yield (89\%, Scheme 2). This method uses oxygen $\left(\mathrm{O}_{2}\right)$ as an economic and green oxidant and water as a green solvent; it tolerates a wide range of substrates, affording the target oximes in moderate to excellent yields. High selectivities were achieved when 3-methyl-4-oxa-5-azahomoadamantane was used as the catalyst and $(E)$-type oximes were the only detected products.

Reusable heterogeneous sandwich-type polyoxometalates were employed as catalysts to convert aliphatic and aromatic aldehydes to corresponding oximes by Zhao and co-authors by using $\mathrm{NH}_{3}$ in the presence of $\mathrm{H}_{2} \mathrm{O}_{2}$ [8]. In a first example, anthracene-9-carbaldehyde (4) was converted into the 9-anthraldehyde oxime (2) by using $\mathrm{Mg}_{3} \mathrm{Al}-\mathrm{Zn}_{5} \mathrm{~W}_{19}$ as the catalyst in 1-butanol as solvent conducting the reaction at room temperature for $6 \mathrm{~h}$. The desired product was isolated in $60 \%$ yield. Higher yields (up to $90 \%$ ) were obtained by using $\mathrm{Na}-\mathrm{Zn}_{5} \mathrm{~W}_{19}$ as the catalyst in water as solvent (Scheme 3 ). However, the best method to prepare the desired oxime 2 remains the classical addition of hydroxylamine to the aldehyde $\mathbf{4}$ in 

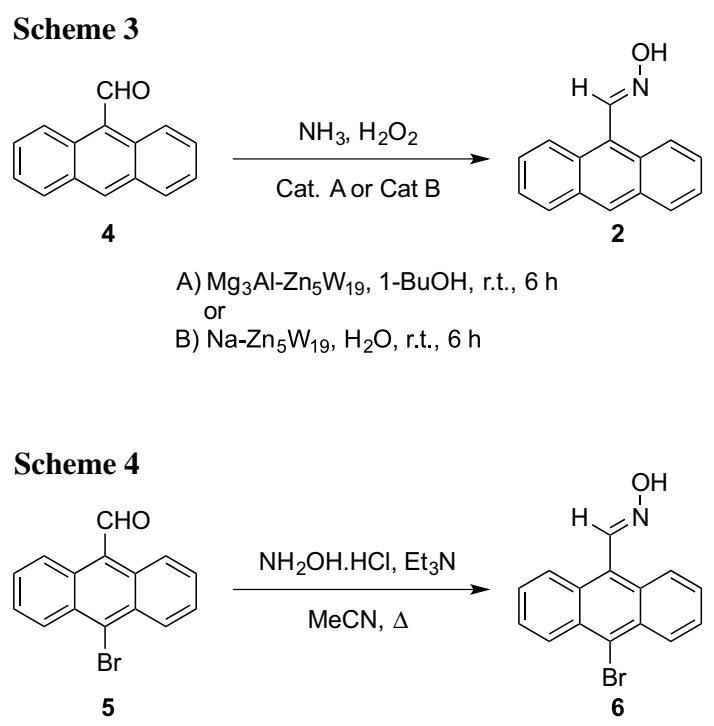

hydro-alcoholic solution affording the oxime with yields in the range $95-99 \%[9,10]$.

We conclude this introductive part dedicated to the synthesis of the anthraldehyde oxime citing an example of a 10 -substituted derivative. The preparation of the 10-bromo9-anthraldehyde oxime (6) was accomplished by starting from the 10-bromoanthracene-9-carbaldehyde (5) with hydroxylamine hydrochloride using freshly distilled triethylamine as a base in anhydrous $\mathrm{MeCN}$ at reflux (Scheme 4). The desired product was isolated in 91\% yield [11].

\section{Synthesis of isoxazoles}

Isoxazoles are valuable heterocyclic compounds, playing an outstanding role in many chemical fields and in particular in medicinal chemistry [12]. The isoxazole core can be found in lots of bioactive natural products and pharmaceutical drugs such as valdecoxib, leflunomide, and cloxacillin [13]. Moreover, isoxazole and its derivatives have a wide range of biological activities, for instance as insecticidal, antibacterial, antibiotic, antitumor, antifungal, antituberculosis, anticancer, and ulcerogenic [14, 15].

A wide variety of synthetic procedures for the formation of the isoxazole core have been reported. Classical methods involve the reaction between hydroxylamine and $\alpha, \beta$-unsaturated carbonyl compounds as well as 1,3 -dicarbonyl compounds and $\alpha, \beta$-unsaturated nitriles. Moreover, $[3+2]$ cycloaddition reactions of alkynes with nitrile oxides are elegant and succinct methods to prepare this class of compounds [16].

Several methods include the use of catalysts and these conditions have been utilized for the preparation of isoxazoles as derivatives of the 9-anthraldehyde oxime (2). Ledovskaya and co-authors [17] reported a simplified
Scheme 5

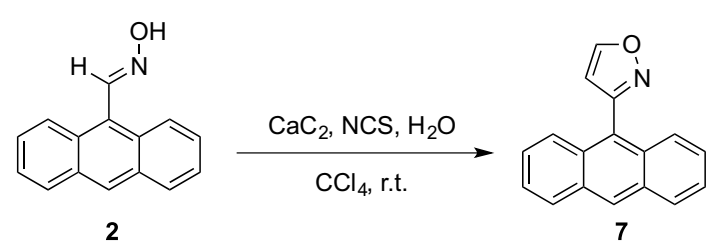

\section{Scheme 6}

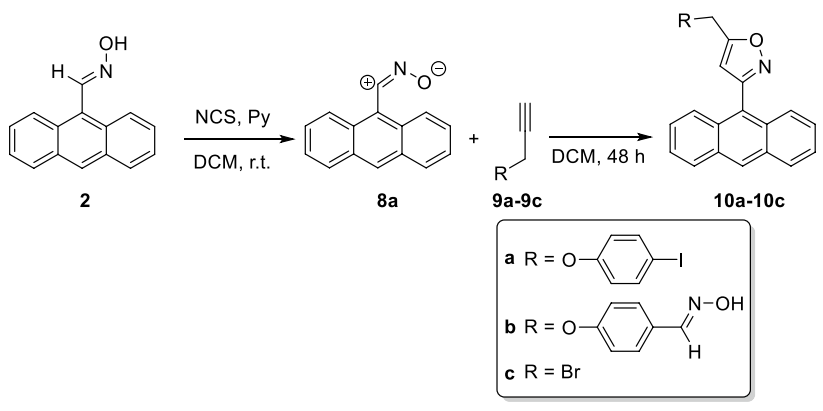

protocol using a one-pot reaction for the synthesis of the 3-(anthracen-9-yl)isoxazole (7); the oxime $\mathbf{2}$ was converted into its chlorinated derivative upon using $\mathrm{N}$-chlorosuccinimide (NCS) and the addition of calcium carbide, as a safe and inexpensive acetylene source and of $\mathrm{Ca}(\mathrm{OH})_{2}$ (the base needed to the in situ generations of nitrile oxide), gave the cycloadduct 7 in $88 \%$ of yield (Scheme 5).

The stable 9-anthracenenitrile oxide (8a) can be easily prepared from the 9-anthraldehyde oxime upon treatment with NCS in basic DCM solution; the stability of the nitrile oxide 8a offers a unique opportunity for an easy and rapid use of this 1,3-dipole in cycloaddition reactions.

We wish to report some examples of 1,3-dipolar cycloadditions with alkynes such as the 1-iodo-4-(prop-2-yn-1yloxy)benzene (9a), 4-(prop-2-ynyloxy)benzaldehyde oxime (9b), and propargyl bromide (9c) that lead to obtain the 3-(anthracen-9-yl)-5-[(4-iodophenoxy)methyl]isoxazole (10a) in 55\% yield, the 4-[[3-(anthracen-9-yl)isoxazol-5-yl]methoxy]benzaldehyde oxime (10b) in $66 \%$ yield and the 3-(anthracen-9-yl)-5-(bromomethyl)isoxazole (10c) in 75\% yield, as single regioisomers (Scheme 6). The synthetic utility of these isoxazoles relies in themselves and upon the ease transformation into enamino ketones as the ligand for the preparation of boron complexes; in fact, after the $\mathrm{N}-\mathrm{O}$ bond cleavage treatment with $\mathrm{BF}_{3} \cdot \mathrm{Et}_{2} \mathrm{O}$ afforded the corresponding boron complexes, suitable for application as fluorescent tags [18-20].

Similarly, Han and Natale [21] has developed a convenient and efficient method for the synthesis of another derivative of the 9-anthracenenitrile oxide (8a) with the dimethylacetylenedicarboxylate leading to the corresponding 3-(9'-anthracenyl)isoxazole-4,5-dicarboxylic acid ester 


\section{Scheme 7}

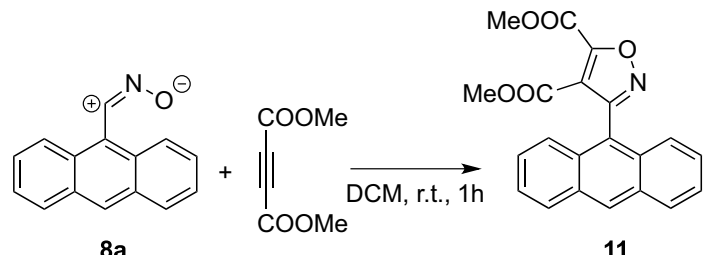

$8 a$

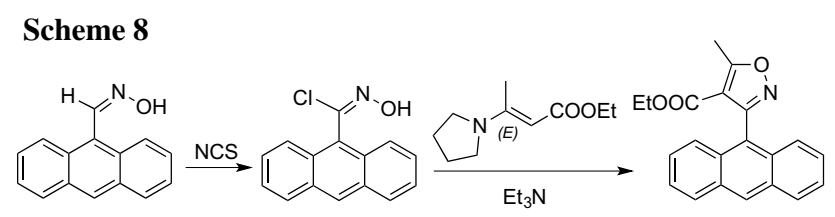

12

11, obtained in good yield (65\%, Scheme 7). Double activation reaction between compound $\mathbf{1 1}$ and hydrogenated lexitropsin, in a 1:2 molar ratio, produced a bis-lexitropsin product (major product) and mono-lexitropsin product, as novel molecule to be used as intercalating part to probe into the G-tetrad pocket; the use of two lexitropsin chains was chosen to preferentially bind to the "ATT" sequence and a potential second site in the G-quadruplex at the same time [21].

A different approach was followed by Natale and co-workers [22] who prepared the ethyl 3-(5-anthracenyl)-5-methyl4-isoxazolecarboxylate (13) through the 1,3-dipolar cycloaddition reaction of the in situ generated nitrile oxide obtained from the of $N$-hydroxyanthracene-9-carbimidoyl chloride (12) (suitably prepared from the reaction of 9-anthraldeyde oxime with NCS) with the ethyl 3-(pyrrolidin-1-yl)

but-2-enoate in absolute ethanol and using triethylamine as base. The cycloadduct $\mathbf{1 3}$ was obtained in $45 \%$ yield and the structure was corroborated through X-ray crystallographic analysis (Scheme 8) [23]. Compound $\mathbf{1 3}$ has been synthesized in view of the investigations related to compound $\mathbf{1 1}$ as an intercalating probe.

The same authors pursued the preparation of anti-tumor DNA-binding lexitropsin molecules including anthracenylisoxazole carboxylates, an intercalating isoxazole molecules, which the anthracene ring was assumed to be able to intercalate between DNA base pairs. In their extensive studies on anthracenenitrile oxides, they described a structural modification on the nitrile oxides moieties through the synthesis of 10-halo ( $\mathrm{Cl}$ or $\mathrm{Br}$ ) anthracene-9-nitrile oxides $\mathbf{8 b}, \mathbf{8 c}$ upon the treatment of 9-anthraldehyde oxime with $N$-halosuccinimides (NCS or NBS) in DMF.

The isoxazolecarboxylic esters 13b, 13c and 11b, 11c were prepared by two different procedures, either via 1,3-dipolar cycloaddition reactions between the obtained nitrile oxides $\mathbf{8 b}, \mathbf{8 c}$ and two different dipolarophiles, ethylpyrrolidino-crotonate (an enamine of ethyl acetoacetate) and dimethyl acetylenedicarboxylate (DMAD), respectively (Scheme 9), or the functionalization of the position 10 of the anthracene ring in isoxazoles 13a or 11a with $N$-halosuccinimide in DMF; in all the cases the chloro derivatives gave greater yields than the bromo derivatives [24]. The same authors [25] demonstrated by X-ray analysis the structure of the isoxazolecarboxylic ester 13c, obtained in $88 \%$ of yield by treatment with NBS.

Some other isoxazole derivatives were prepared by Mirzaei and co-authors [26] in a critical comparison of methods to prepare sterically hindered 3-aryl isoxazoles

Scheme 9
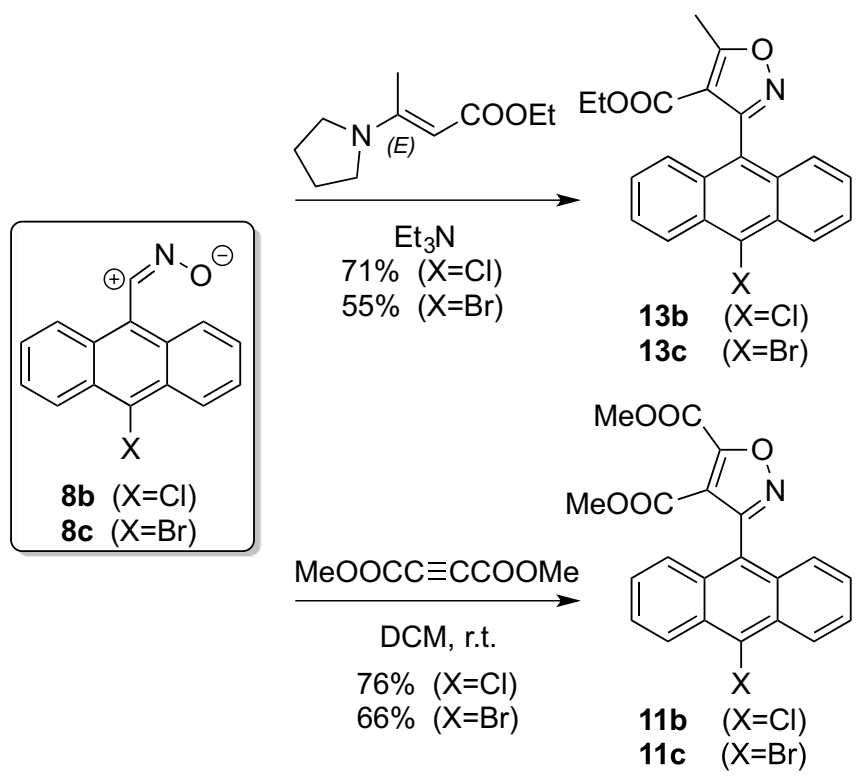<smiles>CCOC(=O)c1c(-c2c3ccccc3cc3ccccc23)noc1C</smiles>

NCS or NBS

DMF, r.t.

$92 \%(\mathrm{X}=\mathrm{Cl})$

$81 \%(\mathrm{X}=\mathrm{Br})$

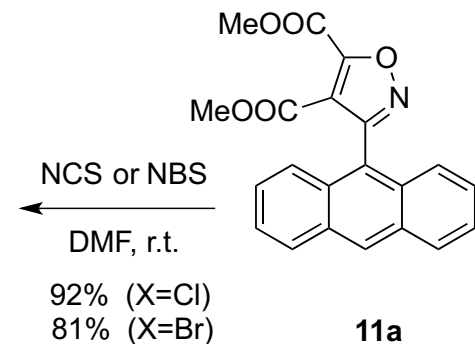

$11 \mathrm{a}$ 

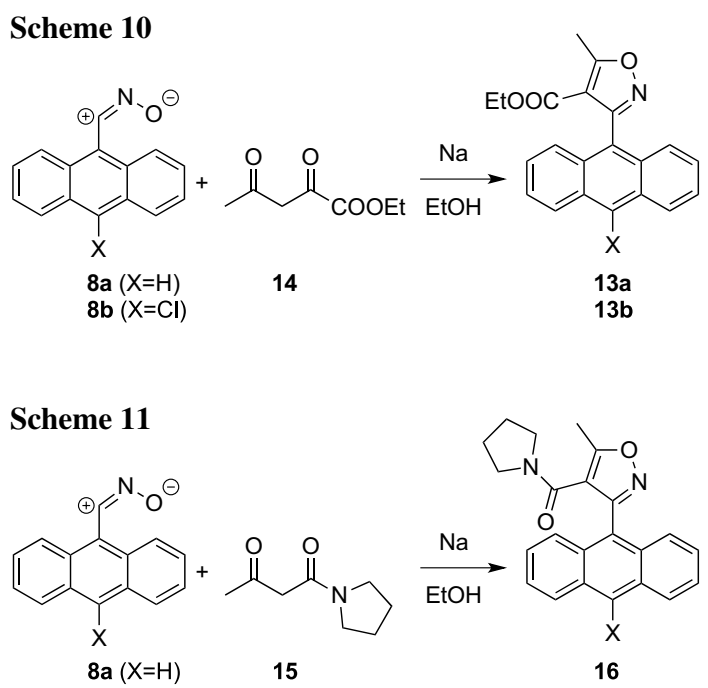

containing fused aromatic rings using the nitrile oxide cycloaddition. It was revealed that modification of the method of Bode, Hachisu, Matsuura, and Suzuki, utilizing either triethylamine as base or sodium enolates of the diketone, ketoester, and ketoamide dipolarophiles, respectively, was the method of choice for these transformations. The reactions between the 9-anthracenenitrile oxide $\mathbf{8 a}$, $\mathbf{8 b}$ and the ethyl 2,4-dioxopentanoate (14) in the presence of sodium ethoxide under Ar atmosphere for $4 \mathrm{~h}$ at ambient temperature afforded the cycloadducts reported in Scheme 10. The ethyl 3-(anthracen-9-yl)-5-methylisoxazole-4-carboxylate (13a) and the ethyl 3-(10-chloroanthracen-9-yl)-5-methylisoxazole-4-carboxylate (13b) were obtained in $94 \%$ and $92 \%$ yield, respectively.

This result prompted the same authors to apply the same reaction conditions using the 9-anthracenenitrile oxide 8a in the presence of ketoamide 15; the [3-(anthracen-9-yl)5-methylisoxazol-4-yl](pyrrolidin-1-yl)methanone 16 was isolated with moderate yield (50\%, Scheme 11) [26].

New chemosensors were designed around a calix[4]arene scaffold, possessing distal isoxazole nuclei as potential recognition sites in conjugation with fluorogenic reporting moieties; they were synthesized and their molecular structures determined by single-crystal X-ray analysis [27]. In fact, Heaney and McGinley reported the reaction of the 9-anthraldehyde oxime with tert-butylphenyl propargyl ether (17) in ethanol in the presence of chloramine-T as the oxidant; the reaction afforded the cycloadduct $\mathbf{1 8}$ in $\mathbf{9 8 \%}$ yield, whose structure was confirmed by X-ray analysis (Scheme 12).

The same methodology was applied in the reaction of 2 with a calix[4]arene derivative $\mathbf{1 9}$ containing two triple bonds and the corresponding bis-isoxazole derivative $\mathbf{2 0}$ was isolated in $51 \%$ yield. Spectrofluorometric studies conducted on the product $\mathbf{2 0}$ showed its selectivity for the recognition of copper(II) ions over a range of divalent metal ions.

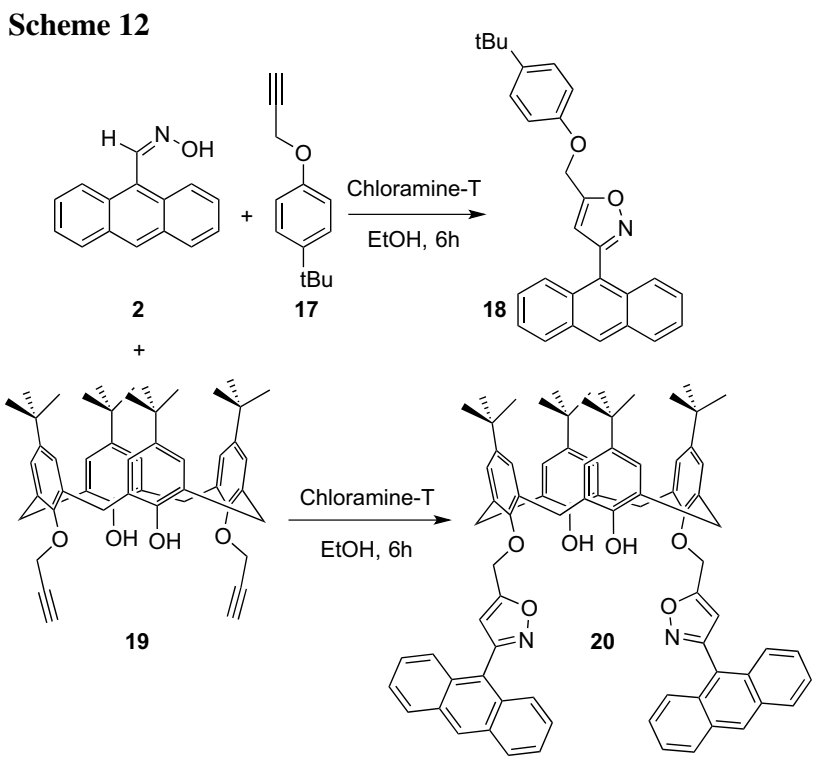

\section{Scheme 13}

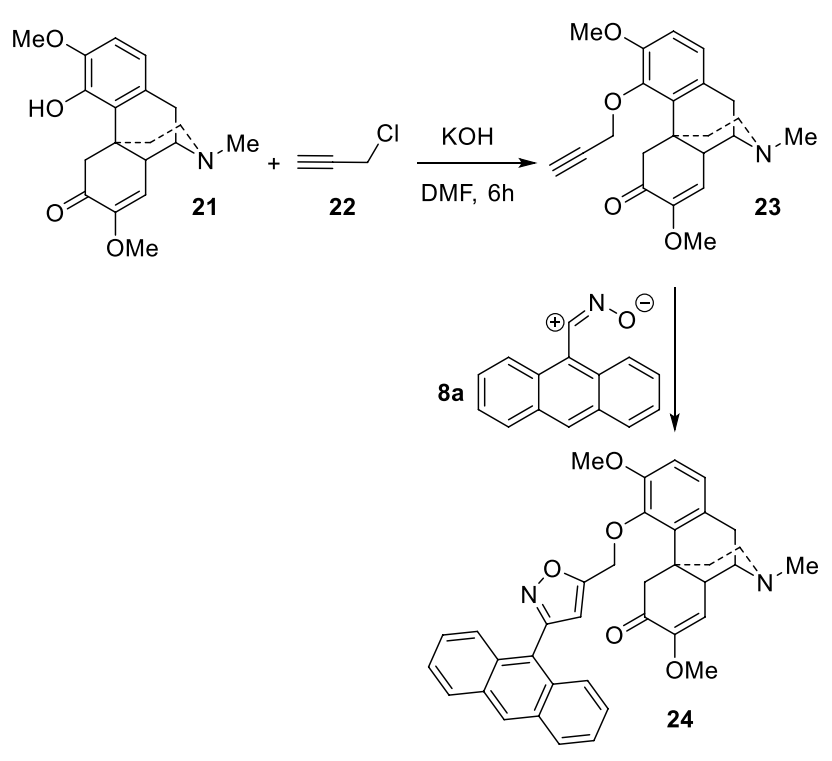

Another effective method has been described for the synthesis of a novel sinomenine isoxazole derivative. Sinomenine is a natural product mainly used for the treatment of rheumatoid arthritis. The sinomenine free base $\mathbf{2 1}$ has been transformed into the 4-alkynyl sinomenine $\mathbf{2 3}$, which is the key intermediate for the synthesis of the target compound. The cycloaddition reaction with 9-anthracenenitrile oxide (8a) afforded the sinomenine isoxazole derivative $\mathbf{2 4}$ in $\mathbf{7 9 \%}$ yield (Scheme 13) [28].

A one-pot three-component synthesis was utilized for the preparation of the [3-(9-anthranyl)-5-(trimethylsilyl)isoxazol-4-yl]ferrocenyl methanone (27) in $62 \%$ yield; the coupling of ethynyltrimethylsilane (26) with ferrocenyl acid chloride (25) under modified Sonogashira conditions 


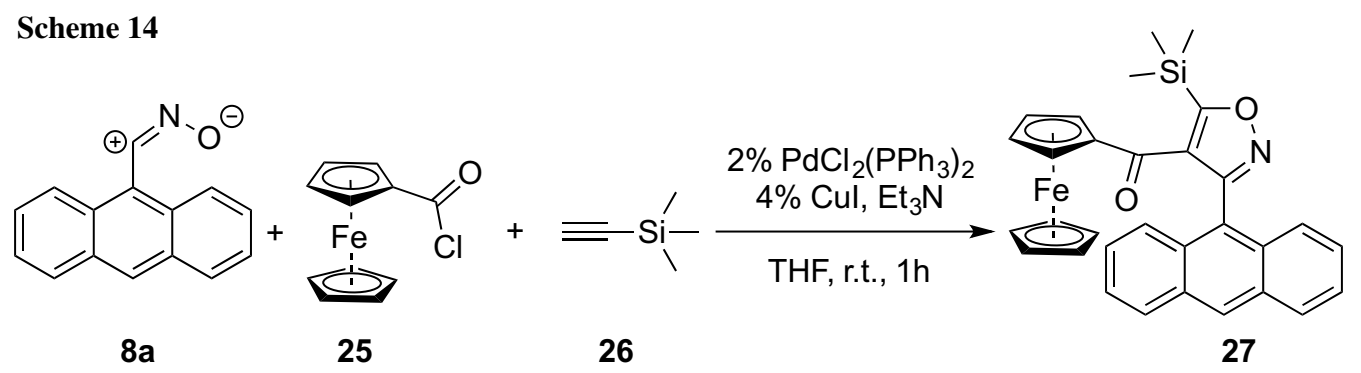

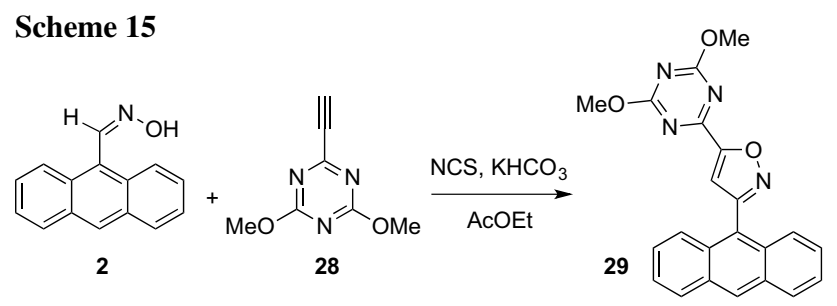

allowed to obtain the predicted alkynones, prone to give the addition of the 9 -anthracenenitrile oxide. The structure of the obtained isoxazole 27 was confirmed by X-ray structure analyses and the electronic structure was elucidated by computational methods (Scheme 14) [16].

Lucescu and co-workers [9] conducted the cycloaddition reaction between the scarcely described 2-ethynyl-4,6-dimethoxy-1,3,5-triazine (28) as dipolarophile and the 9-anthradehyde oxime in the presence of NCS, potassium bicarbonate in ethyl acetate as solvent (Scheme 15). The product, 2-[3-(9-anthryl)isoxazol-5-yl]-4,6-dimethoxy-1,3,5-triazine (29), was obtained in 64\% yield.

Polymer chemistry, probably more than any other chemical discipline, relies on highly efficient organic reactions. Typical macromolecular reactions such as polymer growth, polymer modification, and chain-chain coupling generally require high-yield and highly specific chemical reactions. In that context, it comes as no surprise that modular reactions of the "click"-type have recently been gaining popularity in polymer science. These archetypal "click" reactions open multiple possibilities in terms of macromolecular engineering.
A nice metal-free "click" reaction was investigated to modify polymers through 1,3-dipolar cycloaddition of nitrile oxides and alkynes; 9-anthraldehyde oxime (2) was allowed to react with compound $\mathbf{3 0}$ by using chloramine-T as the oxidant in ethanol as a solvent in the presence of an aqueous solution of sodium bicarbonate to afford the polymeric isoxazole derivative 31, obtained in 95\% yield (Scheme 16) [29]. These cycloaddition appear as promising options for macromolecular engineering and polymer bioconjugation.

\section{Synthesis of oxadiazoles}

Oxadiazoles are other heterocyclic rings that can be prepared from nitrile oxides. Typically, the 1,3-dipolar cycloaddition reactions are conducted in the presence of nitriles as dipolarophiles. In this part of the review, we will present few examples regarding the synthesis of oxadiazole bearing the anthracene moiety derived from the oxime $\mathbf{2}$ source and in close connection with previous investigations conducted in the isoxazole rings.

The 9-anthracenenitrile oxide (8a), prepared according to the well-established methodology already reported, was allowed to react with the calix[4] arenes 32a, 32b to give the corresponding bis-3-(9-anthryl)-1,2,4-oxadiazolyl-5-methylcalix[4]arenes 33a and 33b in 43 and 53\% yield, respectively (Scheme 17) [30]. These compounds were employed as chemosensors selective for $\mathrm{Fe}^{3+}$ without interference by other metals and $\mathrm{Cu}^{2+}$ in particular.

Furthermore, the same authors under the same condition prepared the cycloadducts $\mathbf{3 5 a}$ and $\mathbf{3 5} \mathbf{b}$ in $67 \%$ and $35 \%$ yields, respectively, from the 1,3-dipolar cycloaddition of

Scheme 16

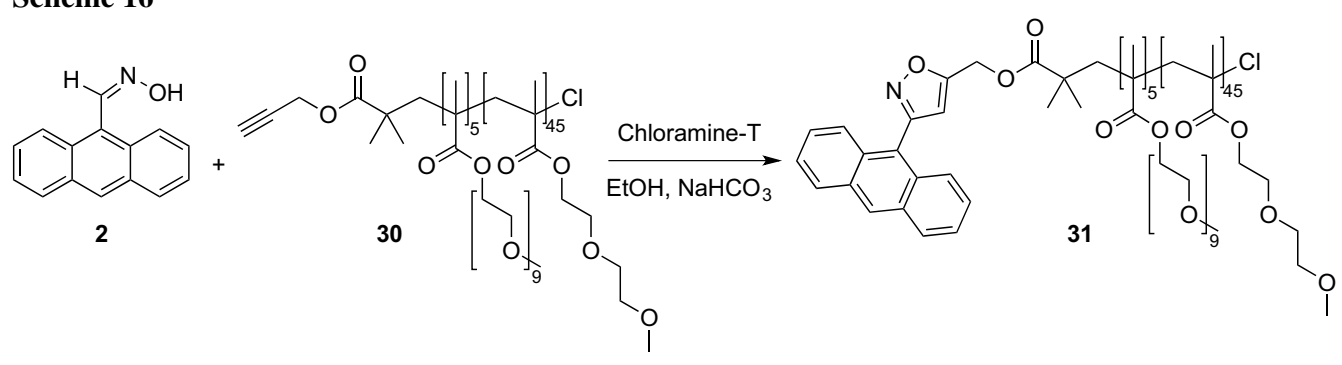




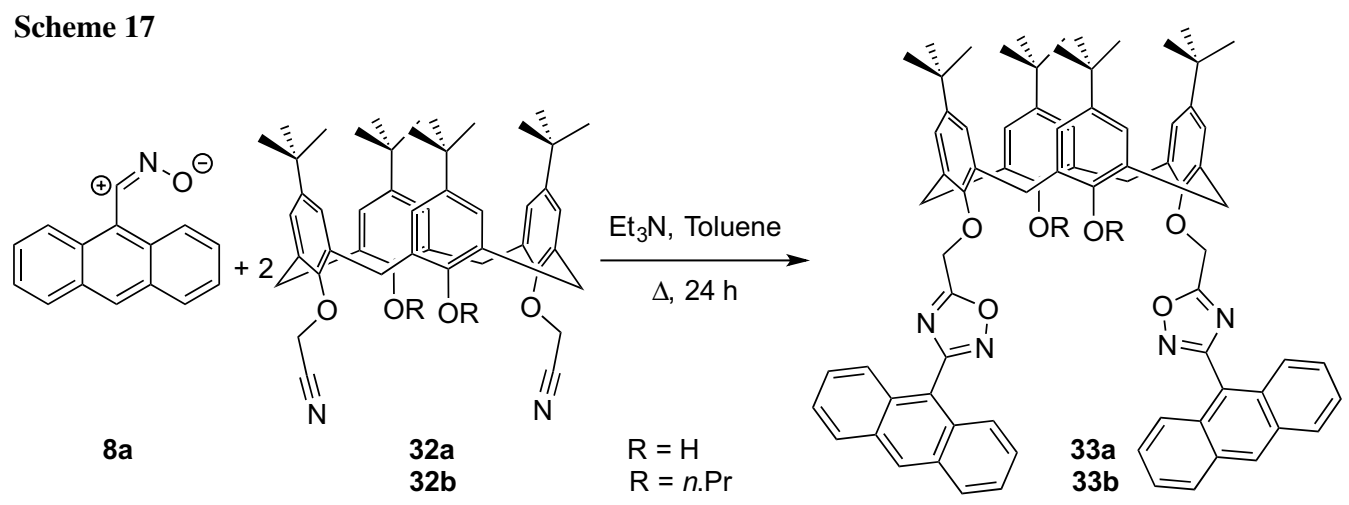

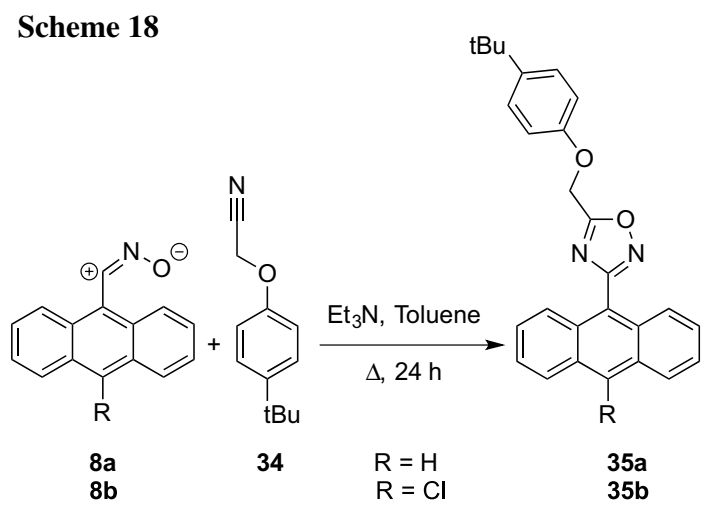

the nitrile oxides $\mathbf{8 a}, \mathbf{8 b}$ with the alkyne 34 (Scheme 18) [30].

\section{Conversion of 9-anthraldehyde oxime to nitrile}

Nitriles are important organic compounds with an extensive range of applications in organic chemistry. The functional group CN has a crucial role in bioactive molecules [31] and serves as a precursor for numerous group transformations e.g., carboxylic acids, aldehydes, amines, amide [32].

Several general methods have been established for the introduction of nitrile groups onto many organic scaffolds [33]. The most common ways to access aliphatic and aromatic nitriles include the nucleophilic substitution of alkyl halides with inorganic cyanides [32], dehydration of amides [34], one pot-conversion of aldehydes to nitriles with inorganic and inexpensive reagents [35], oxidative conversion of primary, secondary, and tertiary amines [36] and Sandmeyer reactions [37]. The conversion of oximes and $o$-substituted aldoximes [38] into nitriles is a remarkable procedure to obtain both aliphatic and aromatic nitriles. Numerous reagents and several conditions have been also developed for the preparation of nitriles by dehydration of aldoximes; this methodology was successfully applied in the dehydration of the 9-anthraldehyde oxime (2) with a variety of catalysts.

\section{Scheme 19}<smiles>O/N=C/c1c2ccccc2cc2ccccc12</smiles>

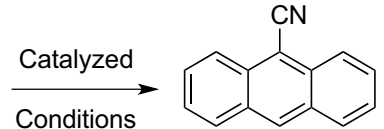

36
Darvish and co-workers [39] proposed a facile method for the dehydration of 9-anthraldehyde oxime by using triphenylphosphine dibromide and $\mathrm{K}_{2} \mathrm{CO}_{3}$ in acetonitrile at room temperature; the anthracene-9-carbonitrile (36) was obtained in excellent yields ( $96 \%$, Scheme 19). The same dehydration has been done with $\mathrm{H}_{2} \mathrm{SO}_{4} / \mathrm{SiO}_{2}$ solid support, under microwave irradiation in dry media; the conversion proceeded in short time and allowed for the obtaining of the corresponding nitrile in high yield (85\%) [40].

Simple Fe(III) salt $\left[\mathrm{Fe}(\mathrm{OTf})_{3}, 10 \mathrm{~mol} \%\right]$ catalyzes the dehydration of the oxime $\mathbf{2}$ in toluene as solvent at reflux overnight and the desired product $\mathbf{3 6}$ was obtained in $\mathbf{9 2 \%}$ yield [41].

Prathepan and co-workers [42] reported the dehydration of 9-anthraldehyde oxime to anthracene-9-carbonitrile in a moderate yield of $53 \%$ but with excellent purities by utilizing Burgess reagent [methyl (carboxysulfamoyl) triethylammonium hydroxide inner salt]. A facile and efficient method for dehydration of 9-anthraldehyde oxime into the corresponding nitrile $\mathbf{3 6}$ took advantage of the use of the $\mathrm{N}$-( $p$-toluenesulfonyl)imidazole (TsIm) in the presence of 1,8-diazabicyclo-[5.4.0]undec-7-ene (DBU) in dimethylformamide (DMF) as a solvent. The corresponding nitrile was obtained in $91 \%$ yield [43].

A new catalytic protocol was applied to convert the 9-anthraldehyde oxime into the corresponding nitrile $\mathbf{3 6}$ using the commercially available Ga(III) triflate as the catalyst in acetonitrile as solvent. In the best condition set up for the reaction ( $5 \mathrm{~mol} \%$ of the catalyst at $85{ }^{\circ} \mathrm{C}$ ) reasonable yields (87\%) were achieved [44]. The simplest dehydration of the commercially available compound $\mathbf{2}$ with malononitrile in the water at reflux for $1.5 \mathrm{~h}$ easily 
afforded the corresponding nitriles $\mathbf{3 6}$ in $87 \%$ yield when in the presence of copper acetate as the catalyst [45].

Lee and co-workers [46] prepared the 9-anthracenecarbonitrile from the 9-anthraldehyde oxime, using 2-chloro1-methylpyridinium iodide (CMPI) as a dehydrating agent in the presence of $\mathrm{Et}_{3} \mathrm{~N}$ in DCM as solvent getting different yields as a function of the experimental conditions. The best results were achieved under Argon atmosphere and the adduct 36 was obtained in 94\% yield while replacing CMPI by diethyl phosphorocyanidate (DEPC) and increasing the time up to $10 \mathrm{~h}$ the yield declined to $81 \%$ [47].

Under Appel-type reaction protocol, the oxime 2 was dehydrated by $\mathrm{CBrCl}_{3} / \mathrm{PPh}_{3}$ in DCM at reflux and using triethylamine as a base, getting the desired nitrile $\mathbf{3 6}$ with $75 \%$ yield [48].

A new mild and reversible method to convert to the corresponding nitrile 36 both syn and anti-isomers of the oxime 2 was described by Partas and co-worker; the yields were excellent $(95 \%)$ by using $\mathrm{Pd}(\mathrm{en})\left(\mathrm{NO}_{3}\right)_{2}$ in acetonitrile at $60{ }^{\circ} \mathrm{C}$ for $16 \mathrm{~h} \mathrm{[49].}$

Polystyrene sulfonate polymer brushes, grown on the interior of the microchannels in a microreactor, were described by Verboom and co-workers and were used for the anchoring of gallium as a Lewis acid catalyst. Initially, gallium-containing polymer brushes were grown on a flat silicon oxide surface and were fully characterized. X-ray photoelectron spectroscopy (XPS) revealed the presence of one gallium per 2-3 styrene sulfonate groups of the polymer brushes. The catalytic activity of the Lewis acid-functionalized brushes in a microreactor was demonstrated for the dehydration of oximes. The catalytic activity of the microreactor could be maintained by periodic reactivation by treatment with $\mathrm{GaCl}_{3}$ [50]. In particular, the conversion of the oxime $\mathbf{2}$ into the corresponding nitrile $\mathbf{3 6}$ showed a relatively poor conversion (19\%). This result can be ascribed to the steric hindrance of the oxime in reaching the catalytically active sites within the polymer brushes. They successfully used $\mathrm{Ga}(\mathrm{III})$ triflate as the catalyst in acetonitrile as solvent at $90{ }^{\circ} \mathrm{C}, 5 \mathrm{~atm}$ pressure, monitoring the conversions by online UV-Vis spectroscopy by following the extinction of the substrate at a specific wavelength. Sardarian and co-workers explored, under milder condition, conversion of the oxime $\mathbf{2}$ into the nitrile $\mathbf{3 6}$ in the presence of diethyl chlorophosphate, getting excellent yields (94\%) and shorter reaction time [51].

Finally, a new catalytic system was proposed by Mandal and co-authors [52] based on the ethyl 2-cyano-2-[[(2nitrophenyl)-di(oxidaneyl)sulfinyl]imino] acetate in the presence of DBU and was found to exhibit valuable dehydration capacity toward the oxime 2 . The reaction afforded the corresponding nitrile 36 in $81 \%$ yield.

\section{Conversion of 9-anthraldehyde oxime into isoxazoline}

Isoxazolines are one of the main $\mathrm{O}$ - and $\mathrm{N}$-containing fivemembered ring heterocycles, which possess substantial synthetic and biological applications. Isoxazolines are the precursors of several multi-functional synthetic intermediates such as $\beta$-hydroxyketones, nitriles, $\alpha, \beta$-unsaturated ketones, oximes, $\gamma$-aminoalcohols, and many others [53, 54]. Isoxazolines represent a unique class of pharmacophores found in many therapeutic agents; they also exhibit interesting and various biological properties. The brominated isoxazoline alkaloids, present in sponges, act as a defense for Tylodina perverse [55]. Nucleosides holding the isoxazoline moiety possess antiviral activities [56]. The therapeutic potential of isoxazoline derivatives is strongly evident from their antimicrobial, anti-inflammatory, fibrinogen receptor antagonistic, anticancer, anti-HIV, caspase inhibitory, and antidepressant properties [57, 58]. 1,3-Dipolar cycloaddition reactions are one of the most important methods for synthesis of isoxazoline and this cornerstone has been introduced by R. Huisgen in the early 1960s [59]. Recently, Quadrelli and co-workers [60] reported the use 1,3-cycloaddition for the synthesis of the fluorescent $(2 S)$-[3-(anthracen-9-yl)-4,5-dihydroisoxazol-5-yl]methyl-2-[(tert-butoxycarbonyl)amino]propanoate (39) in $60 \%$ yield, via reaction of corresponding allyl ester $\mathbf{3 8}$ with the stable nitrile oxide 8a prepared from the corresponding 9-anthraldehyde oxime (Scheme 20). The dipolarophile was prepared from the commercially available $N$-Boc protected $(S)$-alanine $(\mathbf{3 7})$, esterificated through a typical DCC/DMAP coupling procedure with allyl alcohol. The fluorescence properties given by the anthryl moiety of the cycloadduct 39 were determined by recording a fluorescence spectrum in methanol as solvent with an emission maximum located at $481 \mathrm{~nm}$.

A one-pot transformation of aldoximes into isoxazolines through 1,3-dipolar cycloaddition reaction was

\section{Scheme 20}

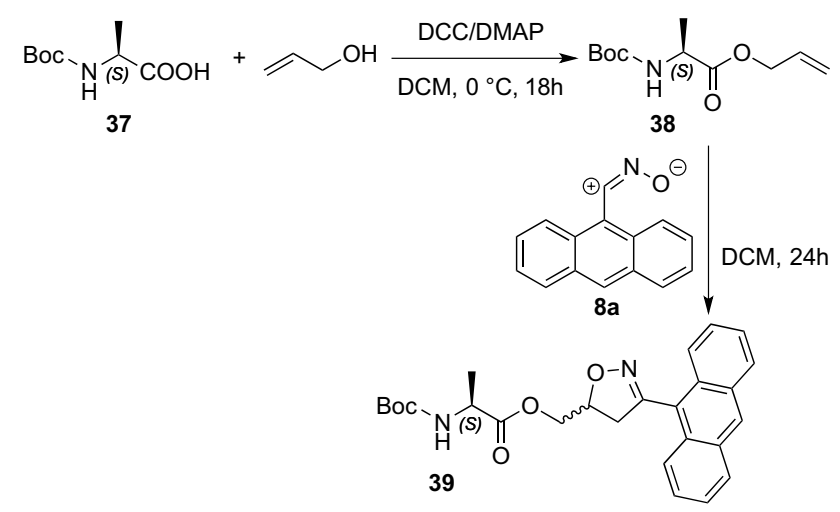


Scheme 21

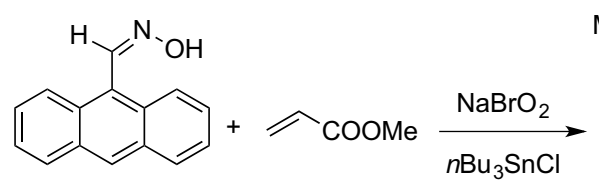

2

Scheme 22
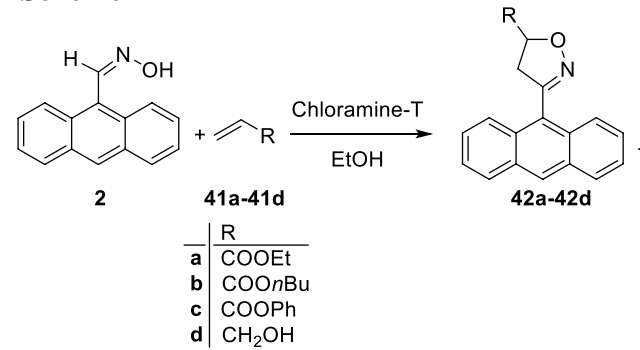

42a-42d<smiles>CC(=O)C1CC(c2c3ccccc3cc3ccccc23)=NO1</smiles>

40

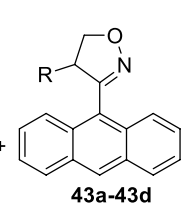

promoted by $\mathrm{NaBrO}_{2}$ and a catalytic amount of tri- $n$-butyltin chloride, with the 9-anthraldehyde oxime $\mathbf{2}$ as starting material for the dipole generation and methyl acrylate as dipolarophile (Scheme 21). The methyl 3-(anthracen-9-yl)4,5-dihydro- isoxazole-5-carboxylate (40) was obtained in $14 \%$ yield [61]. Better yields (68\%) can be obtained upon generating the stable nitrile oxide $8 \mathbf{a}$ by oxidation of the oxime 2 with $\mathrm{NaBrO}_{2}$ and tri- $n$-butyltin chloride and subsequent cycloaddition reaction with methyl acrylate.

A series of isoxazolines was prepared by Rangappa and co-workers [62], through the 1,3-dipolar cycloaddition of in situ generated nitrile oxide $\mathbf{8 a}$ from the 9-anthraldehyde oxime $\mathbf{2}$ in the presence of chloramine-T with a variety of monosubstituted alkenes (Scheme 22). The reactions were highly selective with a neat preference for the regioisomers 42a-42d whose yields range from 65 to $82 \%$.

Anthracenenitrile oxide 8a has been efficiently trapped by the $N$-benzoyl-2,3-oxazanorborn-5-ene (44) that displays a high dipolarophilic activity (Scheme 23). Two regioisomeric cycloadducts $\mathbf{4 5 a}, \mathbf{4 5}$ bere obtained and separated in very good yields (39\% and $47 \%$, respectively) [63]. These compounds were used in synthetic elaboration towards carbocyclic nucleosides with potential antiviral activities [64].
The 3'-(2-methoxy-9-anthryl)isoxazolo[4',5':1,2]-[60] fullerene (47) was prepared from condensation of 2-methoxy-9-anthraldehyde oxime (46) with [58] fullerene and the cycloadduct was obtained in $16 \%$ yield (Scheme 24) [65]. The methodology stands upon the treatment of the oxime with NBS and sodium methoxide. Similarly, new dumb-belltype fullerene cycloadducts 49a, 49b were synthesized via bifunctional nitrile oxide in situ obtained from the bis-oxime 48. The atropic isomers $49 \mathrm{a}, 49 \mathrm{~b}$ were isolated in $6 \%$ and $49 \%$ yields, respectively.

The oxidation of the 9-anthraldehyde oxime (2) by treating in chloroform solution with NCS and catalytic pyridine is a typical method for the nitrile oxide generation. This 1,3-dipole can be store for months without any appreciable decomposition. Moreover, it can be used as it is in the in situ mild generation of the corresponding nitrosocarbonyl intermediate $\mathbf{5 0}$ that reacts with the 3-methylbut-2-en-1-ol in DCM to afford the ene adducts 51a, 51b in 52\% and $27 \%$ yields, respectively (Scheme 25) [66].

The same nitrosocarbonyl intermediate 50, again generated from the oxidation of the oxime $\mathbf{2}$ with the classical methodology, can be also efficiently trapped with an excess of freshly distilled cyclopentadiene to give the corresponding HDA cycloadduct 52 in 61\% yield (Scheme 26) [67].

\section{Conversion of 9-anthraldehyde oxime to aldehyde}

The regeneration of aldehydes from the oxime derivatives is an important process in synthetic organic chemistry that is typically performed through hydrolytic, reductive, or oxidative reactions [68]. From the topic of the present review, the anthraldehyde oxime $\mathbf{2}$ is easily converted into the corresponding aldehyde $\mathbf{4}$ under oxidative conditions by using the cetyltrimethylammonium permanganate (CTAP) as an oxidizing agent in DCM as solvent at $25^{\circ} \mathrm{C}$ (Scheme 27). The reaction is fast ( $15 \mathrm{~min})$ and affords the desired aldehyde in excellent yields $(96 \%)$ and high purity of the final product [69].

Tamami and Yeganeh proposed new different methods with different novel polymer catalysts to conduct the deoximation process. A pyrazine-based polymeric complex of oxodiperoxochromium(VI) $\left(\mathrm{Pyz}-\mathrm{CrO}_{5}\right)_{\mathrm{n}}$ was prepared

Scheme 23

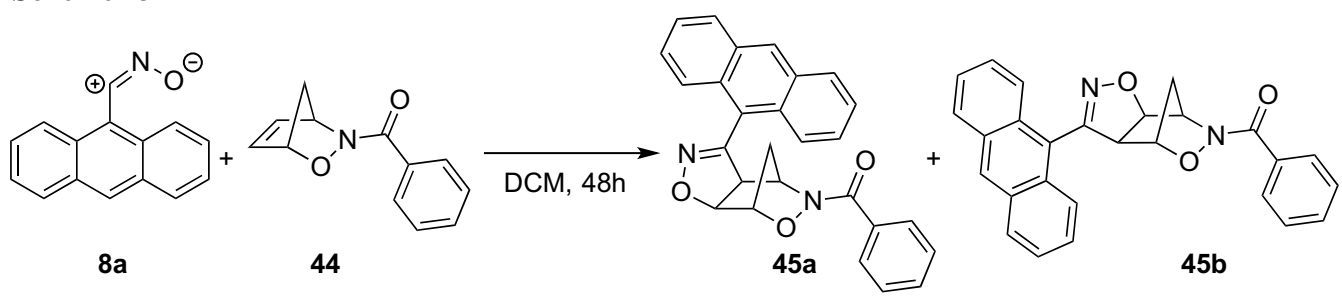




\section{Scheme 24}

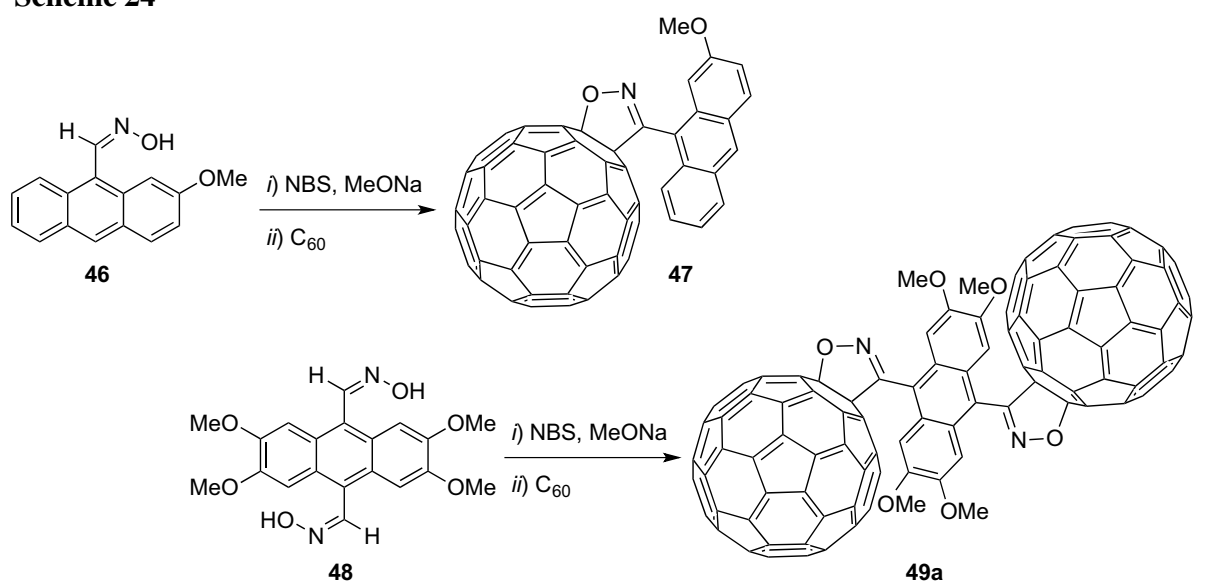

48

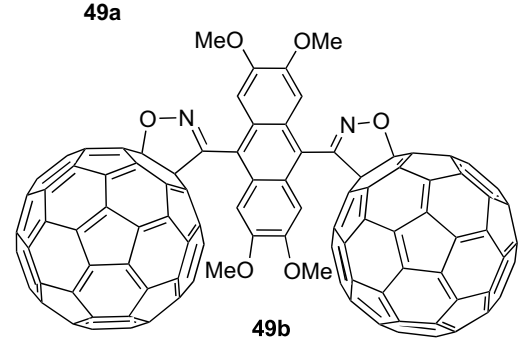

\section{Scheme 25}

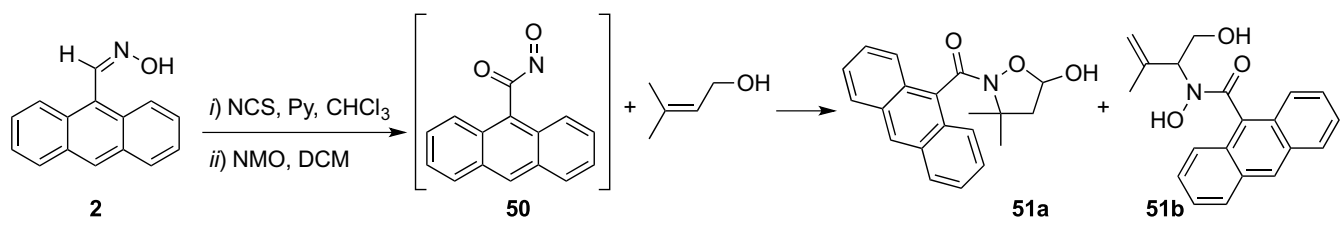

\section{Scheme 26}<smiles>O=NC(=O)c1c2ccccc2cc2ccccc12</smiles>

\section{Scheme 27}<smiles>O/N=C/c1c2ccccc2cc2ccccc12</smiles>

2
Catalyst

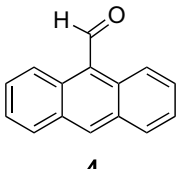

as a new stable form of $\mathrm{CrO}_{5}$ for the efficient oxidation of the oximes; in particular oxime 2 was rapidly oxidized in DCM solution at room temperature getting the aldehyde in $90 \%$ yield [70]. Two new supported anionic peroxomolybdenum complexes inserted on polymer support $[\mathrm{Amb}]_{2}\left[\mathrm{Mo}_{2} \mathrm{O}_{3}\left(\mathrm{O}_{2}\right)_{4}\right]$ and $[\mathrm{Amb}]\left[\mathrm{MoO}\left(\mathrm{O}_{2}\right)_{2}\left(\mathrm{O}_{2} \mathrm{C}-\mathrm{Ph}-\mathrm{NH}_{2}\right)\right]$ 
were also prepared by the same authors as mild, efficient, and versatile oxidants for these reactions and were tested for the conversion of the oxime $\mathbf{2}$ into the corresponding aldehyde $\mathbf{4}$ upon changing the solvent into the 1,2-dichloroethane to increase the reaction temperature at $50{ }^{\circ} \mathrm{C}$. Upon conducting the reaction with a 1:1 molar ratio between the oxidant $[\mathrm{Amb}]_{2}\left[\mathrm{Mo}_{2} \mathrm{O}_{3}\left(\mathrm{O}_{2}\right)_{4}\right]$ and the substrate 2, the desired aldehyde 4 was collected in $89 \%$ yield; conducting the reaction with a 2:1 molar ratio between the second oxidant [Amb] $\left[\mathrm{MoO}\left(\mathrm{O}_{2}\right)_{2}\left(\mathrm{O}_{2} \mathrm{C}-\mathrm{Ph}-\mathrm{NH}_{2}\right)\right]$ and the substrate, a higher yield of 4 was obtained (91\%) [71]. On the basis of these findings, the same authors investigated a polymer-supported anionic peroxotungstate $[\mathrm{Amb}]_{2}\left[\mathrm{~W}_{2} \mathrm{O}_{3}\left(\mathrm{O}_{2}\right)_{4}\right]$ complex as a promising polymeric oxidizing agent for the same purpose to be used under similar experimental conditions; however, the oxidation of 2 required a longer reaction time $(4.2 \mathrm{~h})$ and the aldehyde 4 was isolated in $90 \%$ yield [72].

\section{Conversion of 9-anthraldehyde oxime to amides and amines}

Amides are one of the most vital functional groups in organic and biological chemistry [73], reasonably the most important functional derivatives of carboxylic acids. The reaction of acid chlorides, anhydrides, or esters with amines is the most common and general method for the synthesis of amides. Nevertheless, these procedures are not free from numerous disadvantages, such as the use of toxic, corrosive, and/or expensive materials and in some cases, the reactions are highly exothermic.

In the search of examples regarding the conversion of the oxime of type $\mathbf{2}$ into the corresponding amide, we must remember that Beckmann in 1886 discovered a metal-catalyzed rearrangement of aldoximes, involving the transfer of the group anti to the hydroxyl unit from the carbon to the nitrogen atom, a process that is usually catalyzed by Bronsted or Lewis acids, well known as the Beckmann rearrangement [74]. However, in view of the rearrangement of the oxime 2 to the corresponding primary amide 53, we report that the readily available arene-ruthenium(II) complex $\left[\mathrm{RuCl}_{2}\left(\eta^{6}-\mathrm{C}_{6} \mathrm{Me}_{6}\right)\left\{\mathrm{P}\left(\mathrm{NMe}_{2}\right)_{3}\right\} \mathrm{F}\right]$ can be used as the catalyst $\left(5 \mathrm{~mol} \%\right.$ ) in the reaction performed under $\mathrm{N}_{2}$ atmosphere in the water at $100{ }^{\circ} \mathrm{C}$ with using a Substrate/Ru ratio 100:5

\section{Scheme 28}

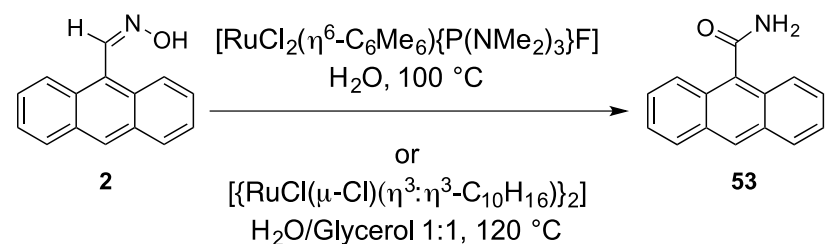

and without the assistance of any co-catalyst; these conditions allowed to obtain the desired amide in high yield (94\%) after $7 \mathrm{~h}$ reaction time (Scheme 28) [75]. In addition, commercially available bis(allyl)-ruthenium(IV) complex $\left[\left\{\operatorname{RuCl}(\mu-\mathrm{Cl})\left(\eta^{3}: \eta^{3}-\mathrm{C}_{10} \mathrm{H} 1_{6}\right)\right\}_{2}\right]$ have already been described as a catalyst for this type of rearrangement both under thermal and microwave heating; when the oxime $\mathbf{2}$ is treated with the Ru catalyst in the ratio 100:5 in a water/glycerol (1:1) mixture as the reaction medium at $120^{\circ} \mathrm{C}$ for $2 \mathrm{~h}$ the desired amide 53 was obtained in 34\% yield; a better result ( $64 \%$ yield) can be achieved by applying microwave irritation for a shorter reaction time at $150{ }^{\circ} \mathrm{C}$ (Scheme 28) [76].

Amines have a great role in organic chemistry and in specific fields of it, e.g. in synthetic materials, in the production of dyes, photographic materials, medicinal and agriculture chemicals, antioxidants, and corrosion inhibitors. The list could be longer as well as that of the methods to prepare them. The reduction of oximes to primary amines is one of the most important and straightforward methods for the preparation of amines [77].

Doreswamy and co-workers successfully converted the oxime 2 into corresponding primary amine $\mathbf{5 4}$ by reduction using the magnesium/ammonium formate protocol; after stirring for $\mathbf{4 0 ~} \mathrm{min}$ at room temperature the oily product $\mathbf{5 4}$ was obtained in $90 \%$ yield (Scheme 29) [78].

In three simple steps, the oxime $\mathbf{2}$ has been converted to the adduct 55 (Scheme 30). In the first step, 9-anthraldehyde oxime was reduced with $\mathrm{LiAlH}_{4}$ in dry THF under Argon atmosphere to get the anthracen-9-ylmethanamine hydrochloride (55) after treatment with $\mathrm{HCl}$. Upon irradiation at $365 \mathrm{~nm}$ of the hydrochloride $\mathbf{5 5}$ in methanol solution for $20 \mathrm{~h}$, compound $\mathbf{5 6}$ was obtained as hydrochloric salt that can be neutralized by treatment with $\mathrm{KOH}$. The desired anthracene-based crosslinked diamine was isolated in $86 \%$ yield, to be utilized to cure a range of commercially available monomers to produce four highly photoreversible crosslinked epoxy polymers [79].

\section{Scheme 29}

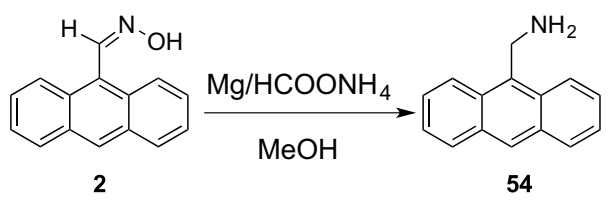

Scheme 30

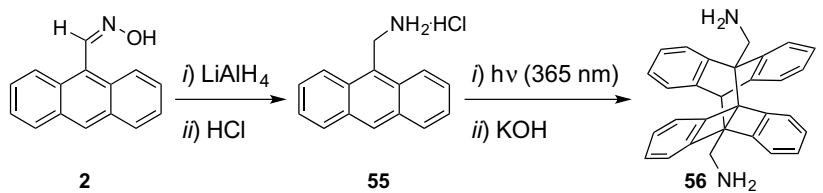




\section{Miscellaneous}

In this paragraph, we collected some other uses and applications of the 9-anthraldehyde oxime (2) where the synthetic targets are various and not included in the previous parts of the present review.

The commercially available oxime $\mathbf{2}$ was used to prepare the 10-nitro-9-anthracenenitrile oxide $(\mathbf{8 c})$; the process starts from the treatment of $\mathbf{2}$ with nitrogen dioxide in dry ether as a solvent and the mechanism relies upon initial nitration on the oxime moiety (intermediate 57) followed by migration to the anthracene ring (intermediate 58) and elimination of $\mathrm{HNO}_{2}$ to give the final 1,3-dipole 8c (Scheme 31) [80].

The 9-anthraldehyde oxime is prone to further derivatization to afford the 9-isothiocyanatoanthracene (60). This derivative was prepared for the first time by Foye and Kauffman, after conversion of the oxime $\mathbf{2}$ into the corresponding nitrile oxide 8a; treatment with carbon disulfide in a pressure vessel at $90{ }^{\circ} \mathrm{C}$ allowed for the obtaining of the desired compound (Scheme 32) [81]. Janovect and co-workers also prepared the same product $\mathbf{6 0}$ in $90 \%$ yield starting from the same nitrile oxide $\mathbf{8 a}$ with potassium thiocyanate in methanol/chloroform as the reaction medium [82].

Saidi and Sheibani described the synthesis of a series of cross-conjugated heterocyclic mesomeric betaines (CCMB) when the oxime 2 was treated with the 3-oxo2-phenylacryloyl chloride (61) in diethyl ether at $0{ }^{\circ} \mathrm{C}$ under a nitrogen atmosphere. A red precipitate of 2-(anthracen-9ylmethylene)-5-oxo-4-phenyl-2,5-dihydroisoxazol-2-ium-3olate (62) was formed instantly in $89 \%$ yield (Scheme 33 ) [83].

Scheme 31

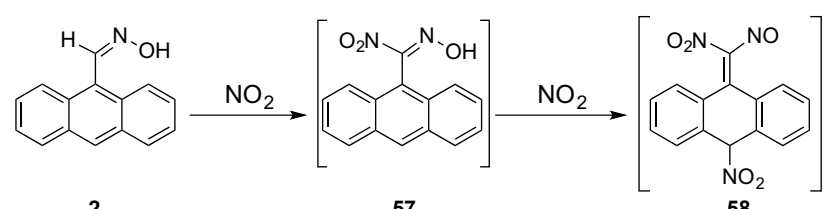

57

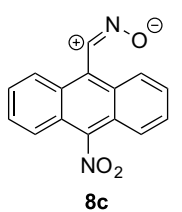

c

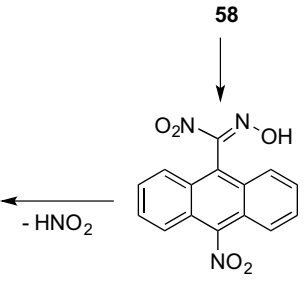

59

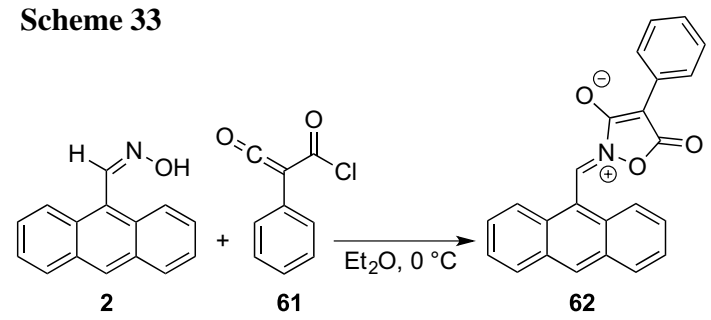

The nitrile oxide $8 \mathbf{a}$, prepared from the oxime $\mathbf{2}$ with NCS in the presence of pyridine at $0{ }^{\circ} \mathrm{C}$ in chloroform, was employed in the addition reaction with the 2,3,4,6-tetra- $O$ acetyl-1-thio-D-glucopyranose (63).

The 1-S-Glucopyranosyl arylthiohydroximate $\mathbf{6 4}$ was thus obtained in excellent yield (95\%). Quantitative deprotection of the sugar unit readily converted the intermediate compounds 64 into the desired non-sulfated artificial glucosinolate $\mathbf{6 5}$ in 89\% yield (Scheme 34) [84].

A new triosmium cluster $\left[\mathrm{Os}_{3}(\mathrm{CO})_{11}\left(\mathrm{C}_{14} \mathrm{H}_{9} \mathrm{CN}\right)\right] \mathbf{7 6 7 7 2}$ was prepared by Wong and co-workers in moderate yield (46\%) upon treatment of the $\left[\mathrm{Os}_{3}(\mathrm{CO})_{11}(\mathrm{MeCN})\right]$ complex 66 with one equivalent of 9-anthraldehyde oxime in refluxing chloroform for $5 \mathrm{~h}$. At the same time, they showed that better results could be obtained when the oxime is replaced with its corresponding nitrile $\mathbf{3 6}$ in DCM as a solvent. The yields are remarkably higher than those reported in the previous case $(72 \%)$. Crystal structure analysis proved that the cluster 67 consists of a triangular metal skeleton, with the anthracene-9-carbonitrile ligand terminally bonded to an osmium atom (Scheme 35) [85].

A platinum complex has been prepared from the oxime 2 when reacted with trans- $\left[\mathrm{Pt}(\mu-\mathrm{Cl}) \mathrm{Cl}\left(\mathrm{PPh}_{3}\right)\right]_{2}$ (68) in 1,2-dichloroethane to afford $\left[\mathrm{PtCl}_{2}\left(\mathrm{PPh}_{3}\right)\right.$ 


\section{Scheme 34}<smiles>[O-]N=C1c2ccccc2[C+]c2ccccc21</smiles>

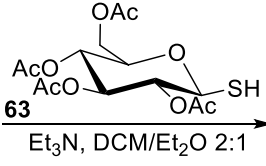

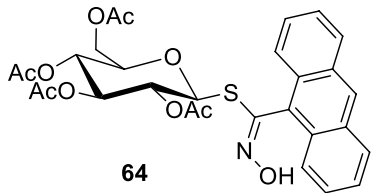

64

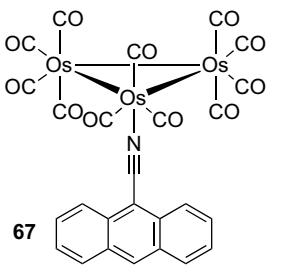

66

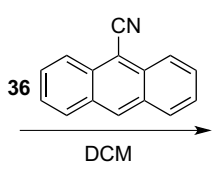

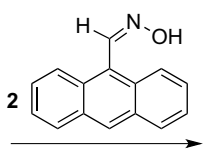

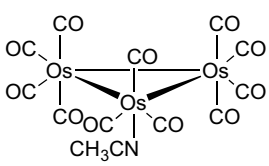

Scheme 35

$\{\mathrm{N}(\mathrm{OH})=\mathrm{CH}(9$-anthryl $)\}]$ 69a, 69b in 54\% yield, where the oxime ligands are $\mathrm{N}$-coordinated to the platinum atom. The complexes are soluble in chlorinated solvents, where they are in equilibrium in the two $(E)$ and $(Z)$ isomers. The equilibrium in solution was studied by ${ }^{31} \mathrm{P}$ NMR spectroscopy and solid-state structural data were obtained by singlecrystal X-ray diffraction studies (Scheme 36) [86].

To conclude, we report a classification model that was developed to provide an accurate prediction of genotoxicity of 277 polycyclic aromatic compounds (PACs) directly from their molecular structures. Numerical descriptors encoding the topological, geometric, electronic, and polar surface area properties of the compounds were calculated to represent the structural information. Each compound's genotoxicity was represented with IMAX (maximal SOS induction factor) values measured by the SOS Chromotest in the presence and absence of $\mathrm{S} 9$ rat liver homogenate. The compounds' class identity was determined by a cutoff IMAX value of 1.25-compounds with IMAX $>1.25$ in either test were classified as genotoxic, and the ones with IMAX e 1.25 were non-genotoxic. Several binary classification models were generated to predict genotoxicity: k-nearest neighbor (k-NN), linear discriminant analysis, and probabilistic neural network. The study showed k-NN to provide the highest predictive ability among the three classifiers with a training set classification rate of $93.5 \%$. A consensus model was also developed that incorporated the three classifiers and correctly predicted $81.2 \%$ of the 277 compounds. It also provided a higher prediction rate on the genotoxic class than any other single model.

The 9-anthraldehyde oxime (CAS 34810-13-4) has been tested for genotoxicity directly from its molecular structure and it was found an IMAX $+\mathrm{S} 9=1.22$; IMAX $-\mathrm{S} 9=1.24$; on this basis compound 2 was found non-genotoxic (class 1) [87]. IMAX is the maximal SOS induction factor, where SOS is a reliable Chromotest for genotoxicity determinations (Scheme 37).

\section{Scheme 36}

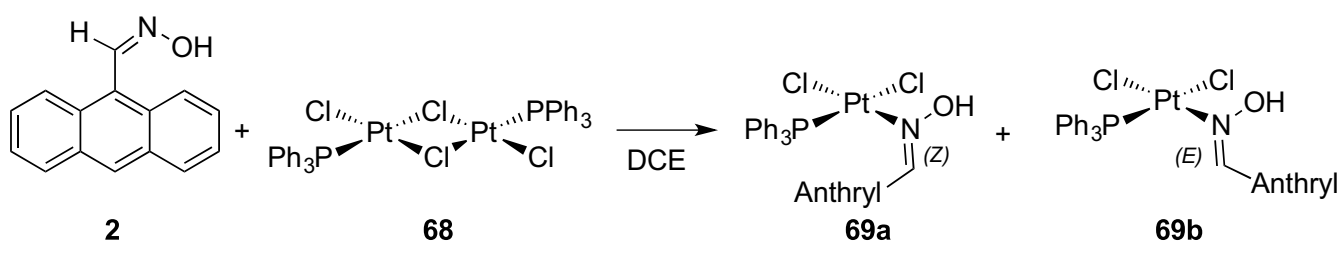




\section{Scheme 37}

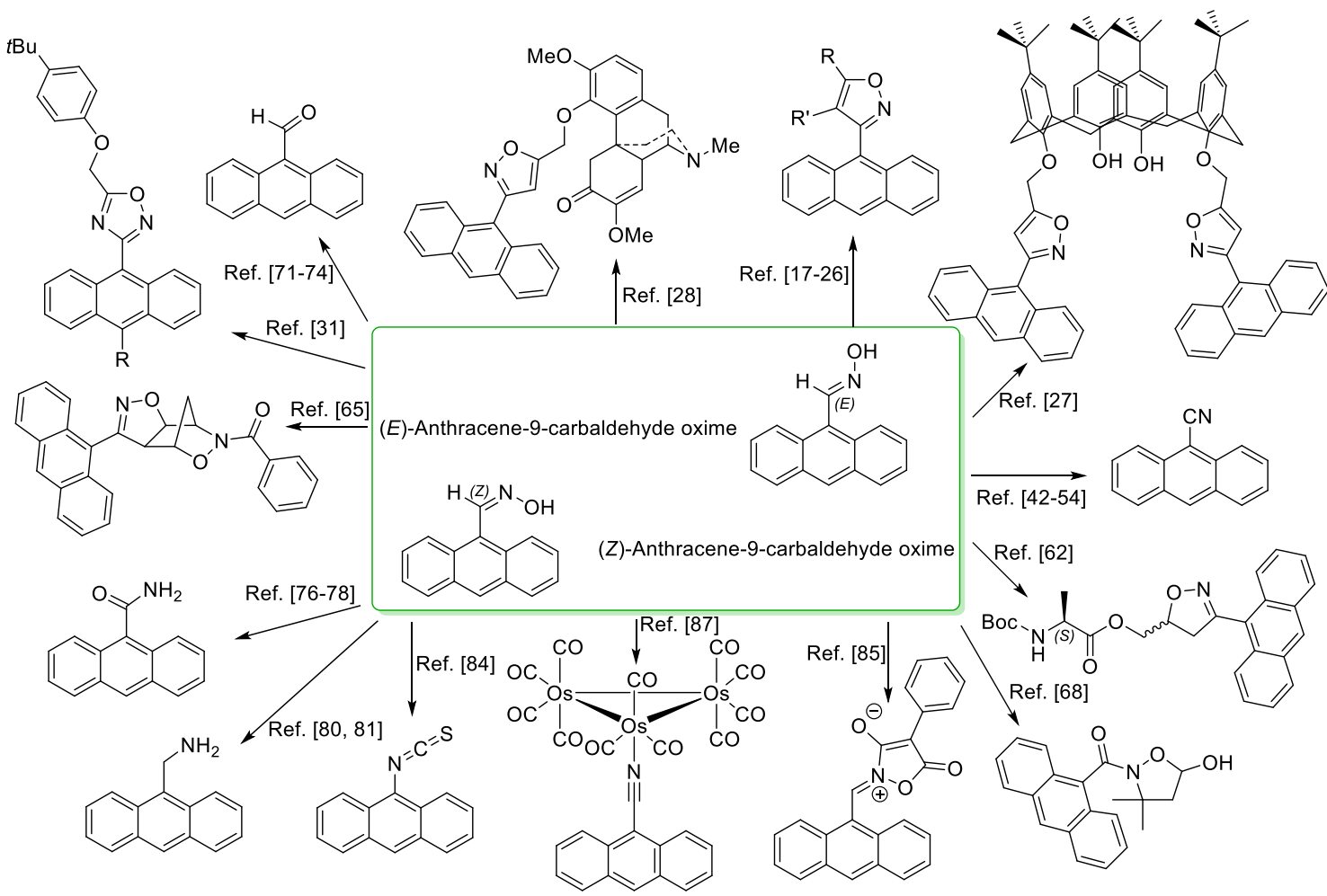

\section{Conclusion}

Surely, oximes are one of the most important and prolific functional groups in organic chemistry; among them, 9-anthraldehyde oxime (2) represents a valuable example both from the preparative side and the synthetic applications. There are many strategies to prepare oxime 2 from different functional groups that were summarized in the present review, focusing on the most recent and innovative. The ease of access to oxime 2 from corresponding aldehydes can be considered as the main method among others. Extremely valuable derivatives such as isoxazoles, isoxazolidines, and oxadiazoles have been prepared from oxime 2 and the best experimental conditions involve its conversion into the corresponding nitrile oxide suitable for 1,3-dipolar cycloaddition reactions with an alkyne and alkenes.

Moreover, a wide range of catalysts through different procedure has been utilized for the conversion of oxime $\mathbf{2}$ into the corresponding nitriles, whereas the best condition is using sulfuric acid as a dehydrating agent upon microwave irritation, albeit the yield is slightly less than other applied procedure. The oxidation of oxime $\mathbf{2}$ is in principle limited to the synthesis of the corresponding aldehyde, e.g. by using cetyltrimethylammonium permanganate (CTAP) as an oxidizing agent; the process proceeded in a shorter time and excellent yields. The acid-promoted Beckmann rearrangement of oxime $\mathbf{2}$ is a very efficient approach for the preparation of amides, while for the conversion into amines the conventional reduction has to be taken in consideration. Furthermore, oxime $\mathbf{2}$ can be converted into isothiocyanates and metal complex derivatives, some of them found to be biologically non-genotoxic.

Acknowledgements University of Pavia is gratefully acknowledged for supporting the research activities and the reported results. We also thank "VIPCAT - Value Added Innovative Protocols for Catalytic Transformations" project (CUP: E46D17000110009) for valuable financial support. We also thank for the financial support the project "Scent of Lombardy" (CUP: E31B19000700007). We finally warmly thank the Hawler Medical University for a grant to S.M.A.

Funding Open access funding provided by Università degli Studi di Pavia within the CRUI-CARE Agreement.

Open Access This article is licensed under a Creative Commons Attribution 4.0 International License, which permits use, sharing, adaptation, distribution and reproduction in any medium or format, as long as you give appropriate credit to the original author(s) and the source, provide a link to the Creative Commons licence, and indicate if changes were made. The images or other third party material in this article are included in the article's Creative Commons licence, unless indicated otherwise in a credit line to the material. If material is not included in the article's Creative Commons licence and your intended use is not permitted by statutory regulation or exceeds the permitted use, you will need to obtain permission directly from the copyright holder. To view a copy of this licence, visit http://creativecommons.org/licenses/by/4.0/. 


\section{References}

1. Rappoport Z, Liebman JF (2009) The chemistry of hydroxylamines, oximes and hydroxamic acids, part 1. Patai series: the chemistry of functional groups. Wiley, Chichester

2. Saikia L, Baruah JM, Thakur AJ (2011) Org Med Chem Lett 1:12

3. Hinkel LE, Ayling EE, Beynon JH (1936) J Chem Soc 1:339-346

4. Fieser LF, Well JLH (1938) J Am Chem Soc 60:2555

5. Meek JS, Dann JR (1955) J Am Chem Soc 77:6677

6. Yu J, Lu M (2015) Org Biomol Chem 13:7397

7. Yu J, Jin Y, Lu M (2015) Adv Synth Catal 357:1175

8. Zhao S, Liu L, Song YF (2012) Dalton Trans 41:9855

9. Lucescu L, Ghinet A, Shova S, Magnez R, Thuru X, Farce A, Rigo B, Belei D, Dubois J, Bîcu E (2019) Arch Pharm Chem Life Sci 352:180

10. Duncan NS, Beall HD, Kearns AK, Li C, Natale NR (2014) Acta Crystallogr Sect E E 70:o315

11. de Montigny F, Argouarch G, Lapinte C (2006) Synthesis 2:293

12. Waldo JP, Larock RC (2007) J Org Chem 72:9643

13. Zhang L, Zeng Q, Mao A, Wu Z, Luo T, Xiao Y, Zhang J (2014) Org Biomol Chem 12:8942

14. Kirshna VC, Raja S (2017) Int J Pharm Pharm Sci 9:13

15. Shailaja M, Manjula A, Rao BV (2011) Indian J Chem 50B:214

16. Willy B, Frank W, Rominger F, Müller TJJ (2009) J Organomet Chem 694:942

17. Ledovskaya MS, Rodygin KS, Ananikov VP (2018) Org Chem Front 5:226

18. Minuti LF, Memeo MG, Crespi S, Quadrelli P (2016) Eur J Org Chem 4:821

19. Moiola M, Crespi S, Memeo MG, Collina S, Overkleeft H, Florea B, Quadrelli P (2019) ACS Omega 4:7766

20. Moiola M, Bova A, Crespi S, Memeo MG, Mella M, Overkleeft HS, Florea BI, Quadrelli P (2019) Chem Open 8:770

21. Han X, Natale N (2001) J Heterocycl Chem 38:415

22. Mosher MD, Natale N (1995) J Heterocycl Chem 32:779

23. Mosher MD, Natale NR, Vij A (1996) Acta Crystallogr Sect C Cryst Struct Commun 52:2513

24. Han X, Twamley B, Natale N (2003) J Heterocycl Chem 40:539

25. Li C, Campbell MJ, Weaver MJ, Duncan NS, Hunting JL, Natale NR (2013) Acta Crystallogr Sect E: Struct Rep Online 69:o1804

26. Mirzaei YR, Weaver MJ, Steiger SA, Kearns AK, Gajewski MP, Rider KC, Beall HD, Natale N (2012) Tetrahedron 68:10360

27. Maher NJ, Diao H, O’Sullivan J, Fadda E, Heaney F, McGinley J (2015) Tetrahedron 71:9223

28. Pan $\mathrm{H}, \mathrm{Lu} \mathrm{T}, \mathrm{Wu} \mathrm{X}, \mathrm{Gu} \mathrm{C}$, Tao N, Zhang B, Wang A, Chen G, Zhang K, Cheng J (2019) Nat Prod Res. https://doi. org/10.1080/14786419.2019.1677649

29. Singh I, Zarafshani Z, Lutz JF, Heaney F (2009) Macromolecules 42:5411

30. Chen YJ, Yang SC, Tsai CC, Chang KC, Chuang WH, Chu WL, Kovalev V, Chung WS (2015) Chem Asian J 10:1025

31. Yadav LDS, Srivastava VP, Patel R (2009) Tetrahedron Lett 50:5532

32. Friedrich K, Wallenfels K (1970) In: Rappaport Z (ed) The chemistry of cyano group. Interscience, New York, $\mathrm{p} 92$

33. Kukushkin VY, Pombeiro A (2002) Chem Rev 102:1771

34. Freidrich K, Wallenfels K (1970) The Chemistry of the cyano group, Wiley, New York, pp 92-93

35. Soli ED, Manoso AS, Patterson MC, DeShong P, Favor DA, Hirschmann R, Smith III AB (1999) J Org Chem 64:3171

36. Bhattacharyya N, Jha S, Jha S, Bhutia TY, Adhikary G (2012) Int J Chem Eng Appl 4:295

37. Iida S, Togo H (2006) Synlett 16:2633

38. Sandmeyer T (1884) Ber Deutsch Chem Ges 17:1633
39. Anand N, Owston NA, Parker AJ, Slatford PA, Williams JM (2007) Tetrahedron Lett 48:7761

40. Darvish F, Movassagh B, Erfani M (2015) Arab J Chem 8:865

41. Kumar HMS, Mohanty PK, Kumar MS, Yadav JS (1997) Synth Commun 27:1327

42. Hyodo K, Kitagawa S, Yamazaki M, Uchida K (2016) Chem Asian J 11:1348

43. Jose B, Sulatha MS, Pillai PM, Prathapan S (2000) Synth Commun 30:1509

44. Rad MNS, Khalafi-Nezhad A, Behrouz S, Amini Z, Behrouz M (2010) Synth Commun 40:2429

45. Yan P, Batamack P, Prakash GKS, Olah GA (2005) Catal Lett 101:141

46. Ma X, He D, Chen Z (2018) J Chem Res 42:595

47. Lee K, Han SB, Yoo EM, Chung SR, Oh H, Hong S (2004) Synth Commun 34:1775

48. Lee KS, An HS, Hwang CY (2012) Bull Korean Chem Soc 33:3173

49. Jasem YA, Barkhad M, Khazali MA, Butt HP, El-Khwass NA, Alazani M, Hindawi BA, Thiemann T (2014) J Chem Res 38:80

50. Tambara K, Pantos GD (2013) Org Biomol Chem 11:2466

51. Munirathinam R, Ricciardi R, Egberink J, Huskens J, Holtkamp M, Wormeester H, Karst U, Verboom W (2013) Beilstein J Org Chem 9:1698

52. Sardarian A, Shahsavari-Fard Z, Shahsavari H, Ebrahimi Z (2007) Tetrahedron Lett 48:2639

53. Dev D, Palakurthy NB, Kumar N, Mandal B (2013) Tetrahedron Lett 54:4397

54. Kamimura A (1992) J Syn Org Chem Jpn 50:808

55. Namboothiri INN, Rastogi N (2008) Isoxazolines from nitro compounds: synthesis and applications. In: Hassner A (ed) Synthesis of heterocycles via cycloadditions I. Springer, Berlin, $\mathrm{p} 1$

56. Thoms C, Ebel R, Proksch P (2006) Sequestration and possible role of dietary alkaloids in the sponge-feeding mollusk Tylodina perverse. In: Molluscs. Springer, Berlin. p 261

57. Venkatesan N, Seo YJ, Bang EK, Park SM, Lee YS, Kim BH (2006) Bull Korean Chem Soc 27:613

58. Imran M, Khan S, Siddiqui N (2004) Indian J Pharm Sci 66:377

59. Habeeb AG, Praveen Rao P, Knaus EE (2001) J Med Chem 44:2921

60. Huisgen R (1963) Angew Chem Int Ed 2:633

61. Memeo MG, Distante F, Quadrelli P (2014) Molbank M837. https ://doi.org/10.3390/M837

62. Moriya O, Nakamura H, Kageyama T, Urata Y (1989) Tetrahedron Lett 30:3987

63. Priya BSB, Rangappa KS (2006) Heterocycl Commun 12:35

64. Memeo MG, Lapolla F, Maga G, Quadrelli P (2015) Tetrahedron Lett 56:1986

65. Moggio Y, Legnani L, Bovio B, Memeo MG, Quadrelli P (2012) Tetrahedron 68:1384

66. Irngartinger H, Weber A, Escher T, Fettel PW (1999) Eur J Org Chem 14:2087

67. Quadrelli P, Mella M, Carosso S, Bovio B (2013) J Org Chem 78:516

68. Savion M, Bovio B, Quadrelli P (2016) ChemSelect 1:1496

69. Huang LH, Lou JD, Zhang C, Lin F, Zou XN (2012) Eur J Chem 9:2141

70. Vankar P, Rathore R, Chandrasekaran S (1986) J Org Chem $51: 3063$

71. Tamami B, Yeganeh H (1997) Tetrahedron 53:7889

72. Tamami B, Yeganeh H (1999) Eur Polym J 35:1445

73. Tamami B, Yeganeh H (2002) React Funct Polym 50:101

74. Crochet P, Cadierno V (2015) Chem Commun 51:2495

75. Gawley RE (2004) Org React 35:1

76. Garcia-Alvarez R, Diaz-Alvarez AE, Borge J, Crochet P, Cadierno V (2012) Organometallics 31:6482 
77. González-Liste P, Cadierno V, García-Garrido SE (2015) ACS Sustain Chem Eng 3:3004

78. Sadighnia L, Zeynizadeh B (2015) J Iran Chem Soc 12:873

79. Doreswamy B, Mahendra M, Mantelingu K, Sridhar M, Prasad JS, Rangappa K (2005) Indian J Chem 4413:148

80. Hughes T, Simon GP, Saito K (2019) ACS Appl Mater 11:19429

81. Suzuki H, Takaoka H, Yamamoto H, Ogawa T (1988) Bull Chem Soc Jpn 61:2927

82. Foye WO, Kauffman JM (1966) J Org Chem 31:2417

83. Janovec L, Suchár G, Imrich J, Kristian P, Sasinková V, Alföldi J (2002) Collect Czech Chem Commun 67:665
84. Saidi K, Sheibani H (2001) Synth Commun 31:1809

85. Brochard L, Joseph B, Viaud MC, Rollin P (1994) Synth Commun 24:1403

86. Wong JS-Y, Lin Z-Y, Wong W-T (2003) Inorg Chem Commun $6: 713$

87. Dell'Amico DB, Colalillo M, Labella L, Marchetti F, Samaritani S (2018) Inorg Chim Acta 470:181

88. He L, Jurs PC, Custer LL, Durham SK, Pearl GM (2003) Chem Res Toxicol 16:1567

Publisher's Note Springer Nature remains neutral with regard to jurisdictional claims in published maps and institutional affiliations. 